\title{
EL ARRAIGO DE PRESOS EXTRANJEROS: MÁS ALLÁ DE UN CRITERIO LIMITADOR DE LA EXPULSIÓN
}

\section{THE ROOTING OF FOREIGN PRISONERS: BEYOND A CRITERION LIMITING THE EXPULSION}

Elisa García-España ${ }^{1}$

Resumen: La política del control de fronteras no solo condiciona, a juicio de los especialistas, la respuesta penal cuando el infractor es un extranjero, sino que también contamina la respuesta al extranjero en el ámbito penitenciario. Con ocasión de la reforma del Código penal (CP) de 2015 en donde se introduce el arraigo de la persona extranjera como elemento limitador de la expulsión en el artículo 89 CP, se reflexiona sobre la posibilidad de trabajar el arraigo de las personas extranjeras presas con una finalidad no solo limitadora de la expulsión penal y administrativa, sino también como factor de protección frente a la delincuencia. Se aportan ideas sobre el tratamiento y régimen penitenciarios orientados a la reinserción de los extranjeros condenados inexpulsables.

Palabras claves: extranjeros delincuentes; prisión; arraigo; expulsión; reinserción.

Abstract: The control migration policy conditions the criminal response when the offender is a foreigner according some experts, and also the response to the foreigner in the penitentiary area. The 2015 reform of art. 89 of Criminal Law introduces the situation of rooting of the foreign person as a limiting element of expulsion. It

1 Instituto de Criminología. Universidad de Málaga 
is proposed to consider the material concept of rooting with other purposes. In Spanish prisons, the number of foreign prisoners on whom expulsion does not fit is significant. Through a broad concept of rooting, understood as limiting expulsion in the criminal sphere and as a factor of protection against crime, we reflect on the treatment and regime of penitentiaries aimed at the reintegration of convicted aliens.

Key words: criminal foreigners; prison; root; deportation; reintegration.

\section{INTRODUCCIÓN}

En el debate presidencial de los EEUU de 2016 la alusión al término "extranjero delincuente" evocaba para un gran segmento de la población estadounidense un odio tangible. En su discurso de inmigración en Arizona, Donald Trump repitió el término "extranjero delincuente" una y otra vez. Mike Pence siguió su ejemplo en el debate de vicepresidentes del 4 de octubre, utilizando el término tres veces para una pregunta sobre la política de inmigración que requería una breve respuesta (Caldwell, 2016).

Pero la campaña de Donald Trump no ha sido la única que ha invocado el término "extranjero delincuente" alentando al odio. Dice Caldwell que el presidente Obama también ha enmarcado sus políticas de inmigración usando esta etiqueta. Ha explicado en múltiples ocasiones que su Administración iba tras "criminales, pandilleros, personas que están perjudicando a la comunidad, no detrás de personas que están aquí tratando de encontrar la forma de alimentar a sus familias". De hecho, en sus planes para la acción ejecutiva de la inmigración, se jactó de que las deportaciones de "delincuentes" habían aumentado al 80\%.

Considera Caldwell que esta demonización de los extranjeros delincuentes, como sujetos malos, carentes de familiares y dignos de un destierro permanente, oscurece los daños que causa la deportación. Etiquetar a los migrantes como "extranjeros delincuentes" eclipsa las complicadas experiencias que hacen que la gente emigre o los fuertes lazos que desarrollan en el país de acogida. Del mismo modo, la etiqueta "extranjero delincuente" oculta las crisis personales que a menudo llevan a las personas a violar la ley, o el perfil racial que conduce a los arrestos desproporcionados de los inmigrantes. 
Sin mucho esfuerzo es posible encontrar en España expresiones de desprecio hacia los extranjeros delincuentes en un sentido similar al señalado por Caldwell. De hecho, la comisión de un delito por parte de un extranjero es la excusa perfecta por parte del legislador para desterrarlo del país (Larrauri, 2016).

La etiqueta de delincuente en ocasiones se utiliza a nivel social como equivalente a peligroso, leproso, escoria... en un intento por restarle dignidad y cosificarlo como objeto peligroso del que hay que protegerse (De Lucas, 2003). A juicio de un número respetado de autores, esto justifica su expulsión, haciendo que la política de control de fronteras desplace los principios de otros sectores del ordenamiento jurídico como pueda ser el ámbito penal (Brandariz, 2011). Esta idea responde al término internacionalmente conocido como "crimmigration" para hacer referencia a la desdibujada frontera entre la política criminal y migratoria, y el sometimiento de aquella a favor de esta (Stumpf, 2006).

En el caso español tenemos algunos ejemplos que mantienen esta tesis. Por una parte, los extranjeros con antecedentes penales, según se recoge en la Ley de Extranjería (LE), no son bienvenidos, siendo aquellos un filtro para la selección que administrativamente se hace de los extranjeros a los que se les concede visados y permisos de residencia (Larrauri, 2016). Si bien es posible comprender que se exija este tipo de requisitos a los extranjeros que pretenden entrar en el país, este supuesto difiere bastante de los casos en los que el extranjero ya reside en él y, por diferentes circunstancias, acaba delinquiendo y cumpliendo condena en España. En este caso, no todos los extranjeros que delinquen en España se encuentran en las mismas circunstancias en cuanto a gravedad del hecho, tiempo de residencia, posibilidades de materializar la expulsión, lazos con el país, entre otros. Es por ello que el principio de individualización de la pena, los fines de la misma y la orientación resocializadora en su ejecución, deberían permitir que, en ciertos supuestos, el extranjero preso pudiera contar con una segunda oportunidad. Para estos casos, sin embargo, nuestro ordenamiento jurídico se ha venido dotando de diferentes armas para expulsar de una forma u otra al extranjero que ha delinquido en España: la primera de ellas es el archivo de la causa penal contra el extranjero con la única pretensión de eliminar los obstáculos para su expulsión administrativa recogida en el artículo 57.7 LE. El ámbito penal, que prima siempre frente a decisiones administrativa de acuerdo con el principio de subsidiariedad 
de este sobre aquel, se pliega ante estos casos, renunciando a sus fines de prevención general y especial. De esta manera se consigue "favorecer la realización de los fines de la política inmigratoria" que corresponde al Gobierno según art. 2 bis LE, en detrimento de los principios penales. Otro instrumento con el que el ordenamiento jurídico se arma frente al extranjero delincuente es la expulsión como sustitución total o parcial de la pena de prisión del art. 89 CP. En los casos en los que el juez considera que por razones de prevención general, positiva o negativa, o de prevención especial el extranjero debe cumplir la condena en España, entonces se prevé su expulsión tras pasar un tiempo en prisión o, en todo caso, al alcanzar el tercer grado o la libertad condicional. La evidente vulneración del principio non bis in ídem, o prohibición de castigar dos veces por un mismo hecho, queda claramente vulnerado en esta regulación (González Tascón, 2016; Yáñez Velasco, 2015), volviendo a primar de forma evidente la política del control de fronteras (Brandariz, 2011) frente a principios constitutivos del Derecho penal. Si a pesar de todo lo anterior, el extranjero condenado termina cumpliendo toda la pena, quedando en libertad en España, entonces tenemos una tercera forma de deportar al extranjero y es a través de la expulsión administrativa del país por incurrir en una infracción consistente en tener antecedentes penales (“...el extranjero haya sido condenado, dentro o fuera de España, por una conducta dolosa que constituya en nuestro país delito sancionado con pena privativa de libertad superior a un año..." art. 57.2 LE), aun cuando ya ha saldado su deuda con la justicia y se le supone en un proceso de reinserción social.

Por otro lado, el Ministerio del Interior en sus Balances anuales de lucha contra la inmigración irregular muestra al extranjero delincuente como la antítesis del inmigrante trabajador. Así se aprecia en el cambio que ha experimentado la forma de dar la información sobre el número de expulsiones incoadas, distinguiendo entre expulsiones cualificadas y no cualificadas (Martínez Escamilla, 2016). Según el Balance de 2015 son expulsiones cualificadas aquellas que recaen sobre "extranjeros reincidentes, autores de hechos de especial violencia o gravedad, terroristas, presos a los que se les sustituye la pena, están en prisión preventiva o concluyen su condena", $\mathrm{y}$ las no cualificadas las que recaen sobre extranjeros con mera estancia irregular en España. De esta manera, se pretende ahondar en la diferencia entre extranjeros delincuentes y no delincuentes, y autocomplacerse por el alto número de expulsiones "cualificadas" 
que se han incoado ( $80 \%$ aproximadamente del total) frente a las "no cualificadas". Todo ello además de la crítica que merece el hecho de que se incluya en un mismo concepto (cualificadas) categorías tan distintas como, por ejemplo, terroristas y presos preventivos (Boza, 2016; Martínez Escamilla, 2016).

En este contexto se intenta también justificar la existencia de los Centros de Internamiento de Extranjeros, argumentando que muchos de los extranjeros que allí se internan tienen antecedentes penales. De esta manera, el hecho de haber cometido en el pasado un delito parece justificar la existencia de centros denigrantes e injustos a juicio del Defensor del Pueblo, de autos de jueces de control de CIE (entre otros, Auto 53/2017, de 8 de mayo de 2017 del Juzgado de Instrucción $\mathrm{n}^{\circ} 1$ de Algeciras, Cádiz) e informes de entidades sociales, cuyo objetivo es privar de libertad al inmigrante por no tener una autorización administrativa de residencia y donde se vulneran los derechos humanos amparados por la opacidad y la falta de transparencia de lo que allí ocurre (Daunis, 2015, Informe SJM 2016, entre otros muchos). A mayor abundamiento, estamos ante una institución ineficiente, pues no consigue en la mayoría de los casos su propósito final que es la expulsión del extranjero internado (Boza, 2016; Garcia España, 2017). Frente a las voces que arremeten contra este tipo de instituciones anómalas y fracasadas (Ríos Martín, 2014; Daunis Rodríguez, 2015; Martínez Escamilla, 2016, Solanes, 2016, Boza 2016, García España, 2017 entre otros), aflora el alegato de la supuesta peligrosidad de los extranjeros internados, intentando legitimar las documentadas respuestas excepcionales sobre personas que además de extranjeras son "delincuentes".

Por último, es tan eficiente acudir a la etiqueta de extranjero delincuente que en la última reforma del Código penal de 2015 (operada por Ley Orgánica 1/2015, de 30 de marzo, por la que se modifica la L.O. 10/1995, de 23 de noviembre, del Código penal) se ha incluido en el artículo 89 del CP la posibilidad de expulsar al extranjero delincuente aun cuando este es residente legal.

Con todo, es evidente que el hecho de que una persona extranjera cometa un delito lo coloca, según los fines de la expansiva política migratoria, en una situación muy complicada en caso de que quiera mantenerse en el país. Se opera, desde el anunciado concepto internacional conocido como "crimmigration", un desplazamiento de los fines de la política criminal y penitenciaria, a favor del control de fronteras (Stumpf, 2006), arrebatando a la pena de prisión su 
orientación hacia la reeducación y la reinserción social establecida constitucionalmente (art. 25.2 Constitución española) y en el art. $1^{\circ}$ de la Ley Orgánica General Penitenciaria (LOGP). Y si consigue quedarse en el país, al colarse por los múltiples resquicios que toda esta arquitectura jurídica tiene, la condena a la exclusión social está más que servida, ya que los antecedentes penales le impide acceder a una autorización de residencia, elemento esencial para desarrollar una vida integrada e inclusiva en sociedad (Larrauri, 2016).

Ante este panorama, estamos de acuerdo con Caldwell en que se hace necesario desafiar el constructo "extranjero delincuente" y tratar de trabajar por reformas de extranjería y derecho penal más inclusivas que reconozcan la posibilidad de que las personas pueden cometer errores y volver a empezar. Trataremos en las siguientes páginas de aportar algunas ideas que se apoyan en la última reforma del art. 89 del CP y que se encaminan a desafiar los derroteros de exclusión del "extranjero delincuente" a través de un nuevo escenario para los ejecutores de la norma, especialmente los del ámbito penitenciario.

\section{ESCENARIOS DE ACTUACIÓN PENITENCIARIA CON PERSONAS EXTRANJERAS PRESAS}

En el ámbito penitenciario hay al menos dos itinerarios a la hora de abordar la intervención con los internos extranjeros no comunitarios (Nistal, 2013; Circular 1/2013, de modificación de la Circular 1/2012, sobre extranjería en centros penitenciarios de Cataluña). El primer escenario tiene que ver con la reintegración en el país de todos aquellos extranjeros con una situación administrativa regularizada o con arraigo suficiente. En este caso la Administración penitenciaria desarrolla dos tipos de actuaciones: por una parte, las encaminadas a demostrar la situación administrativa anterior al ingreso y mantenerla actualizada con base en datos objetivos; y, por otra, a tratar de regularizar la situación de aquellos internos que cumplen las condiciones objetivas requeridas en la legislación vigente.

El segundo escenario es el retorno al país de origen de todos aquellos extranjeros a los que sea imposible regularizar administrativamente su situación en el país. En estos casos es conveniente agilizar los trámites cuando la probabilidad de materializar la expulsión u otras posibilidades de repatriación es alta. La resocialización pasa en estos 
supuestos por intentar evitar la desocialización que un tiempo más prolongado del necesario en prisión puede causar en el sujeto o reforzar su arraigo en origen. Desgraciadamente, en el caso de los presos extranjeros, el tiempo de permanencia en prisión condicionada por la ejecución de la expulsión no parece que sea una decisión judicial o del equipo de tratamiento, sino más bien se hace depender en muchos casos de las posibilidades reales de materializarla por parte de la policía.

Pero con frecuencia nos encontramos ante un tercer escenario. Son los supuestos en los que el extranjero no cuenta con las circunstancias objetivas requeridas para ser regularizado en el país, no puede ser expulsado por razones legales o materiales que se abordarán a continuación y no quiere ser trasladado a su país de origen para cumplir condena. Se desconoce el volumen de este grupo pero, según algunas estimaciones, las expulsiones judiciales ejecutadas a presos extranjeros serían tan solo de un $22 \%$ de los extranjeros excarcelados en España cada año por extinción de su condena (Nistal, 2013).

Los supuestos de hecho en los que la expulsión, penal o administrativa, no se puede ejecutar tienen que ver con el arraigo declarado en sentencia condenatoria o probada con posterioridad (art. $89 \mathrm{CP}$ ); con la condición de apátridas, asilados, refugiados y protegidos internacionalmente mientras mantengan dicho estatus; $y$ los que con la expulsión se pone en riesgo su vida o su salud, bien por circunstancias personales del sujeto o bien por la situación del país; por estar indocumentados; los que no son reconocidos o aceptados por sus país de origen; los que no se consigue conocer su nacionalidad; los que se rebelan e impiden la materialización de la expulsión; etc.

En este trabajo se tratará de poner en valor, a partir de la inclusión del arraigo como elemento limitador de la expulsión penal del art. 89 del Código penal (CP) tras la reforma de 2015, el arraigo del extranjero en el país no solo como impedimento a la expulsión, sino como factor de protección delictivo y reinserción futura. El objetivo de estas páginas es mostrar la necesidad de trabajar en la reinserción de unos extranjeros presos a los que no se les va a aplicar la expulsión por diferentes motivos y a los que desde instituciones penitenciarias se les debe ofrecer las mismas estrategias tratamentales que a un nacional con base en el principio de igualdad y no discriminación. La creación y fortalecimiento de vínculos con la comunidad de acogida se propone como un elemento imprescindible en el proceso de reinserción de estos extranjeros. 


\section{EVOLUCIÓN DEL NÚMERO DE EXTRANJEROS DELINCUENTES PRESOS}

Durante años, y según los datos de World Prison Brief, España ha sido uno de los países con mayor tasa de población penitenciaria de Europa. En concreto, en 2009 la tasa era de 160 presos por cada 100.000 habitantes, situándose a la cabeza de los países europeos de su entorno. En la actualidad, no obstante, España se sitúa en un cuarto lugar con una tasa de 136 presos por cada 100.000 habitantes y por detrás de Inglaterra y Garles (148), Escocia (143), Portugal (136).

Este descenso en el ranking europeo del primer al cuarto puesto en tan solo un quinquenio se debe a una disminución general de la población penitenciaria española, como se aprecia en el siguiente gráfico 1, dándose ese descenso tanto en la población extranjera como en la nacional:

\section{GRÁFICO 1}

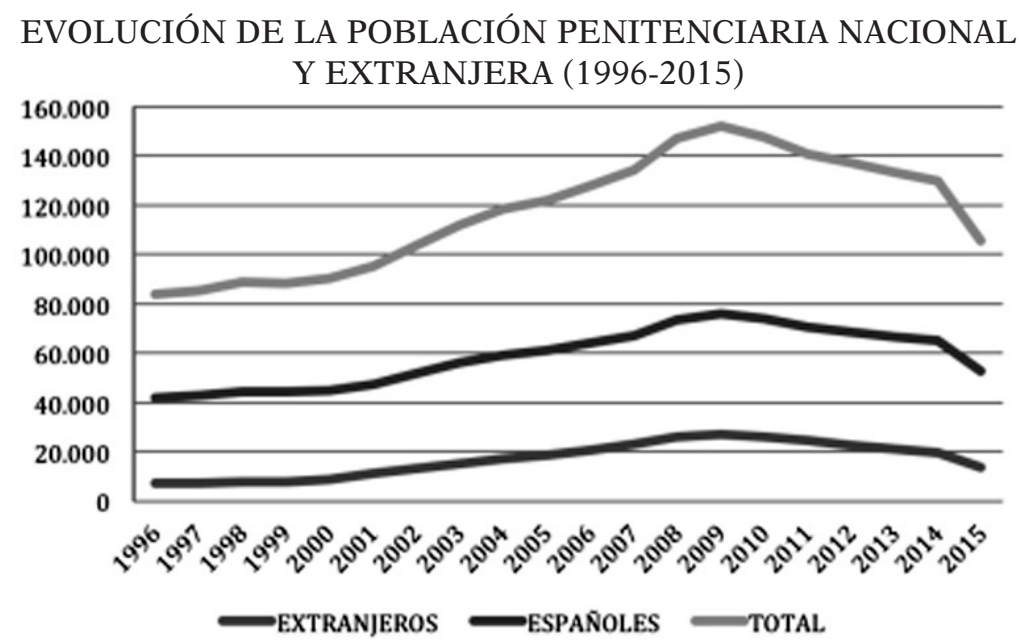

Fuente: elaboración propia a partir de los datos del Ministerio del Interior.

Son varios los motivos que pueden explicar este descenso de la población presa en España. Algunos autores han tratado de argumentar tal descenso a través de razones de política criminal, política de extranjería y política penitenciaria. 
Por una parte, casi todos los autores coinciden en señalar que los cambios político-criminales en materia de drogas operado por la Ley Orgánica 5/2010, de 22 de junio, tienen algo que ver con este descenso de población penitenciaria (Brandariz, 2015; Cerezo y Arenas, 2016; Daunis, 2016; Montero y Nistal, 2014; Montero y Ravagnani, 2016; Cid Moliné, en prensa). De hecho, con esta reforma se redujo el máximo del intervalo de pena de prisión que imponía el artículo $368.1 \mathrm{CP}$, transformándose el intervalo de pena de 3 a 9 años antes de la reforma, a de 3 a 6 años tras la reforma de 2010. Acudiendo solo a datos oficiales no podemos saber si el descenso está motivado por la modificación de la pena del artículo $368.1 \mathrm{CP}$, ni tampoco el impacto que ello ha tenido sobre la población extranjera presa. No obstante, un indicio del impacto de esta reforma es que el porcentaje de condenados por delitos contra la salud pública en general descendió de 27,6\% en 2010 a 23,8\% en 2015 (Cerezo y Arenas, 2016). Dentro de la corriente punitivista que ha caracterizado la política criminal española (Díez Ripollés, 2008) esta reforma es una excepción, pero no parece que sea capaz de explicar por sí sola el descenso de población penitenciaria experimentado por España en los últimos años, especialmente porque el descenso de población penitenciaria se inició antes de que entrara en vigor esta reforma.

Por otra parte, hay autores que apuntan a razones de política de extranjería sobre la base de que el descenso de población presa en general descansa en cierta medida en la reducción de presos extranjeros. Ciertamente estos han pasado de representar en España un $35,6 \%$ del total de la población penitenciaria en 2010 a un $28 \%$ en 2016 (según datos de World Prison Brief). La razón se encuentra para algunos en el aumento del número las expulsiones cualificadas (Brandariz, 2015; Montero y Ravagnani, 2016) en contraposición a las expulsiones no cualificadas. Siguiendo los datos de dichos Balances anuales, las expulsiones cualificadas aumentan porcentualmente con respecto a las no cualificadas. Sin embargo, observando los datos en términos absolutos no se puede afirmar que las expulsiones cualificadas sean las causantes de una reducción significativa del número de presos extranjeros, puesto que, lejos de aumentar, han descendido de 9.114 en 2011 a 5.539 en 2015.

La misma conclusión se alcanza si acudimos a los datos del Informe 2015 de Instituciones Penitenciarias donde se desglosan los distintos conceptos por los que puede ser excarcelado un extranjero y que se exponen en la tabla 1. Entre 2010 y 2015 el número total 
de estas excarcelaciones descendió de 14.369 a 10.395. Hay que tener en cuenta que de las cifras totales de excarcelaciones, el 75\% aproximadamente corresponden a libertad provisional, libertad condicional y extinción de la condena en España y éstas han ido aumentando proporcionalmente frente a las deportaciones. Todas éstas disminuyeron durante ese tiempo en términos absolutos de 3.855 deportaciones en 2010 a 2.411 en 2015, manteniéndose anualmente en un 15\% con respecto a la población presa extranjera. Solo la expulsión judicial tras cumplir las tres cuartas partes de la condena o alcanzar la libertad condicional (art. 89.5 CP anterior a la reforma de 2015) aumentó de 97 casos en 2010 a 263 en 2015. Ni el aumento de las expulsiones del art. 89.5 CP, ni la evolución general de todas ellas explican el descenso de la población extranjera en prisión.

\section{TABLA 1}

TIPOS DE EXCARCELACIÓN DE EXTRANJEROS

\begin{tabular}{|c|c|c|c|c|c|c|}
\hline Tipo de excarcelación & $\begin{array}{l}\text { Año } \\
2010\end{array}$ & $\begin{array}{l}\text { Año } \\
2011\end{array}$ & $\begin{array}{l}\text { Año } \\
2012\end{array}$ & $\begin{array}{l}\text { Año } \\
2013\end{array}$ & $\begin{array}{l}\text { Año } \\
2014\end{array}$ & $\begin{array}{l}\text { Año } \\
2015\end{array}$ \\
\hline $\begin{array}{l}\text { Expulsión administrativa con autorización } \\
\text { judicial de preventivos (art. } 57.7 \text { Ley } \\
\text { Orgánica Extranjería } 8 / 2000 \text { ) }\end{array}$ & 84 & 98 & 69 & 71 & 64 & 54 \\
\hline $\begin{array}{l}\text { Expulsión judicial sustitutiva de la pena } \\
\text { aplicable (pena inferior a } 6 \text { años. Art. } 89.1 \\
\text { del Código Penal) }\end{array}$ & 930 & 724 & 671 & 579 & 456 & 418 \\
\hline $\begin{array}{l}\text { Expulsión judicial al cumplimiento de } 3 / 4 \\
\text { partes de condena } 0 \text { al tercer grado (Art. } \\
89.5 \text { del Código Penal) }\end{array}$ & 97 & 93 & 143 & 225 & 213 & 263 \\
\hline $\begin{array}{l}\text { Traslado a país de origen para } \\
\text { cumplimiento de condena (Convenio de } \\
\text { Estrasburgo y Otros Tratados Bilaterales) }\end{array}$ & 257 & 181 & 226 & 186 & 163 & 152 \\
\hline $\begin{array}{l}\text { Libertad condicional (Art. } 197 \text { del } \\
\text { Reglamento Penitenciario) }\end{array}$ & 640 & 942 & 626 & 509 & 470 & 414 \\
\hline Libertad Provisional & 5.220 & 4.786 & 4.360 & 4.071 & 3.337 & 3.048 \\
\hline Extinción de condena* & 4.063 & 3.874 & 3.937 & 3.724 & 3.675 & 3.640 \\
\hline Orden Europea de detención y entrega & 942 & 966 & 851 & 714 & 733 & 607 \\
\hline Extradición & 96 & 69 & 73 & 85 & 102 & 86 \\
\hline Libertad condicional en España & 1.231 & 1.626 & 1.473 & 1.347 & 1.229 & 1.216 \\
\hline Otros & 809 & 815 & 684 & 638 & 596 & 497 \\
\hline Totales & 14.369 & 14.174 & 13.113 & 12.149 & 11.038 & 10.395 \\
\hline
\end{tabular}

Fuente: Informe 2015 Instituciones Penitenciarias. 
Por otro lado, Cid Moliné apunta también a estrategias de política penitenciaria tendentes a aumentar el uso de la libertad condicional en los últimos años. De hecho, los datos de Instituciones penitenciarias muestran que el decreciente uso que se hacía de la libertad condicional durante la fase de expansión penitenciaria anterior al 2010 (con un promedio de 13 libertades condicionales otorgadas por cada 100 presos condenados) se está revirtiendo en el último período al aumentar a 16 por cada 100 presos condenados. Sin embargo, los datos oficiales sobre el número de libertades condicionales concedidas no soportan este argumento para esta población en concreto. Tampoco los números avalan que las repatriaciones (Montero y Nistal, 2014), fruto de la aplicación del Convenio de Estrasburgo u otros convenios bilaterales, así como del art. 197 del Reglamento Penitenciario (RP), sean las causantes de dicho descenso.

Ninguna de las decisiones de política criminal, de política de extranjería y de política penitenciaria expuestas hasta ahora parece explicar por completo el descenso de población carcelaria, y menos aún la reducción de población extranjera penada en prisión. Puede ayudar a entenderlo el descenso de población extranjera en España con motivo de la recensión económica. Entre 2011 y 2016 el número de extranjeros en España descendió en 893.543, según datos de población a 1 de enero de 2016 del Instituto Nacional de Estadística. Si desglosamos dicha población por edades, se observa que las que más descienden son las comprendidas entre los 20 y los 39 años, que es la franja etaria que presenta mayor riesgo de tener contacto con el sistema penal. De hecho, el porcentaje de imputaciones y detenciones de extranjeros, según el Anuario estadístico 2015 del Ministerio del Interior, ha disminuido con respecto al total (de 31,57\% en 2009 a 24,14\% en 2015). También las entradas en prisión desde libertad han descendido. Entre 2010 y 2014 entraron en prisión 9.287 personas menos, dato similar al correspondiente descenso de población carcelaria entre 2010 (76.701) y 2014 (66.857) que ha sido de 9.844 presos menos. De las 9.287 entradas menos en prisión en ese quinquenio, 5.078 corresponde a nacionales y 4.209 a extranjeros. Por tanto, parece que detrás del descenso de la población penitenciaria extranjera se encuentran varios motivos relacionados con el descenso de población extranjera, la disminución del número de entradas en prisión y la reducción de penas del art. 368.1 CP. Por el contrario, la repatriación en sus múltiples variantes, si bien permite ser un 
instrumento de reinserción para un determinado grupo de extranjeros (Montero y Nistal, 2014) sin arraigo en el país y con deseo de volver a su lugar de origen, no permite explicar el descenso de la población penitenciaria extranjera, por lo que se torna como instrumento ineficiente en caso de querer ser utilizado para descongestionar las prisiones o luchar contra la inmigración irregular.

\section{EL ARRAIGO COMO ELEMENTO DE PERMANENCIA Y REINSERCIÓN PARA EXTRANJEROS DELINCUENTES}

\subsection{La novedad del arraigo en el ámbito penal}

La reforma de 2015 del Código penal trajo consigo una modificación sustancial de algunas figuras penales, entre ellas, la expulsión como sustitutivo de la pena de prisión. Entre las grandes novedades que aparecen en la regulación de esa expulsión penal recogida en el art. 89 $\mathrm{CP}$ destaca, entre otras, la referencia a un juicio de proporcionalidad cuyos criterios a considerar son "las circunstancias del hecho y personales del autor, en particular el arraigo". De esta forma, el legislador incorpora como novedad en el Código penal de 2015 los criterios de la jurisprudencia del Tribunal europeo de derechos humanos (TEDH), permitiendo en cierta medida la individualización de la pena a los extranjeros (Roig Torres, 2014). El arraigo del extranjero es por tanto un límite frente a la expulsión no solo en el momento de dictar sentencia, sino también en el momento de su ejecución. De esta manera, la consideración de la expulsión como desproporcionada a la luz de dichos criterios supondría una limitación absoluta a su ejecución (Circular Fiscalía General del Estado, 2015).

Por tanto, nos encontramos por primera vez con una formulación expresa en el ámbito penal con la que se brinda la posibilidad de modular la respuesta penal a los extranjeros que delinquen a través de una ponderación del arraigo como un valor a proteger y la expulsión como una intromisión que hay que justificar. Con esta nueva redacción del art. 89 CP se evitan sentencias como la de la Sala de lo Contencioso administrativo del Tribunal Superior de Justicia de Andalucía, (sentencia de 13 de marzo de 2012) en la que se argumentaba que el arraigo familiar alegado no podía servir para evitar la expulsión en el supuesto de autos de condena privativa de libertad superior a un año 
al estar la consecuencia expresamente establecida en la ley, por lo que la anulación de la sanción supondría dejar de aplicar la ley.

Procede a continuación definir qué se entiende por arraigo en el ámbito penal. El arraigo es un concepto jurídico indeterminado en nuestro ordenamiento jurídico al que hay que dotar de contenido. Como todo concepto jurídico indeterminado presenta contornos vagos e imprecisos que exigen determinar qué factores la integran (Carbajal, 2012). Desde mi punto de vista, existen al menos dos criterios que nos permiten avanzar en la delimitación del concepto de arraigo.

\subsection{El concepto formal de arraigo}

El criterio formal entiende que hay arraigo atendiendo a ciertas pruebas que presumen la existencia de vinculación con el país, pero sin preocuparse de si dichos vínculos son efectivos. Este criterio es propio del ámbito administrativo cuyo fin es el control de fronteras y la regulación de los flujos migratorios en función de las necesidades del mercado de trabajo y de la economía del país. Su alcance es limitado, puesto que la presunción requiere exigencias formales rigurosas. Sin embargo, ha sido un concepto que ha calado en algunos tribunales y también en el ámbito penitenciario.

Hacen remisión a este criterio, por ejemplo, la Circular 1/2013, de modificación de la Circular 1/2012, sobre extranjería en centros penitenciarios de Cataluña y el art. 57.5 LE. La Circular de la administración penitenciaria catalana hace referencia al arraigo como algo diferente a la vinculación familiar, al tiempo de permanencia, a los lazos laborales y a la situación de regularidad. De hecho, esa Circular se remite al concepto de arraigo incluido en el art. 57.5 LE, donde se presume el arraigo por haber nacido en España y haber residido legalmente los últimos 5 años, por ser nacional de origen que hubiese perdido la nacionalidad, por ser beneficiario de una prestación por incapacidad permanente para el trabajo como consecuencia de un accidente de trabajo o enfermedad profesional ocurridos en España, así como por percibir una prestación contributiva por desempleo o ser beneficiario de una prestación económica asistencial de carácter público destinada a lograr su inserción o reinserción social o laboral. Igualmente se consideran arraigados los cónyuges de extranjeros en alguna de esas condiciones si han residido legalmente en España durante 
más de dos años, y a sus ascendientes e hijos menores o mayores discapacitados. Es decir, estos son los supuestos, junto con la residencia de larga duración que a diferencia de los anteriores sigue un criterio material según mi opinión, en los que la Ley de Extranjería entiende que no debe procederse a la expulsión administrativa pues la mera demostración de alguna de esas circunstancias presume la existencia de arraigo. Evidentemente, en el ámbito penitenciario, que debe valorar a fondo las circunstancias del penado para la toma de decisiones regimentales y tratamentales, este concepto formal de arraigo queda bastante estéril. De ahí que la propia Circular catalana acude a otros criterios para complementar dicho "arraigo formal", como son la vinculación familiar en España y especialmente en Cataluña; el tiempo de permanencia en España y especialmente en Cataluña; la experiencia laboral demostrable en territorio español; situación socio-familiar, etc.

Si bien el Tribunal Supremo (TS) y el Tribunal Constitucional (TC) atienden a criterios materiales, hay jurisprudencia de otros órganos judiciales que mantienen este criterio formal de arraigo. En concreto, el Tribunal Superior de Justicia del País Vasco (Sala

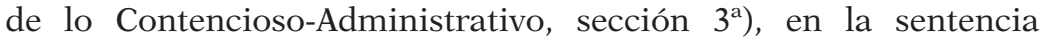
núm. 327/2014, de 21 mayo, entiende que cuando no se den los presupuestos contemplados en el apartado $5^{\circ}$ del art. 57 LE, éste no pueda ponderarse. Se trata de un caso en el que se produce una aplicación automática de los mecanismos de expulsión sin tener en cuenta las circunstancias personales y familiares del autor, y concretas del hecho, como se establece en las normas y jurisprudencia internacionales.

\subsection{El concepto material de arraigo}

Con este criterio material se busca la existencia de unos vínculos efectivos y no se presumen. No se conforma con la existencia del vínculo, sino que exige que los mismos sean de una calidad suficiente como para arraigar al sujeto en la comunidad. Sobre esta concepción material hay a su vez dos formas de concebir el arraigo con alcance diferenciado: Por una parte, está la postura que considera el arraigo como un derecho de primer orden del extranjero que hay que proteger frente a la pretendida expulsión administrativa o penal. Este es el criterio del TEDH y que sigue la Circular 7/2015 FGE. 
La otra forma de concebir el arraigo desde un concepto material es como un factor de protección frente al delito y necesario de cara al desistimiento y a la reinserción social. Esta es la perspectiva criminológica con la que no solo se trabaja el desistimiento, sino también la reinserción social del interno, siendo este un concepto más próximo a la inclusión social (Hirschi, 1969; Laub y Sampson, 2003; Laub, Sampson y Wimer, 2006). A continuación desarrollamos ambas posturas complementarias, y en ningún caso encontradas, ya que las dos confluyen en el extranjero condenado a pena de prisión.

\subsubsection{El arraigo como limitador de la expulsión penal}

Es la jurisprudencia del TEDH la que a través de los diferentes litigios desentraña las virtualidades que encierran los respectivos derechos humanos y perfila su contenido. Es por ello que los derechos fundamentales tienen carácter esencialmente jurisprudencial (Díaz Fraile, 2015). Al ser el arraigo un concepto jurídico indeterminado que contiene derechos humanos de primer orden que hay que proteger, su contenido viene perfilado por la jurisprudencia del TEDH. En ninguna otra parte viene recogido que ha de entenderse por arraigo a estos efectos.

Para el TEDH el arraigo de una persona en un país diferente al suyo compromete derechos de los de más alto rango recogidos en el art. 8 de la Convención europea de Derechos Humanos (CEDH). Este tribunal se basa principalmente en atender al concepto de arraigo familiar como circunstancia limitadora de una decisión de expulsión tomada por los organismos internos de un Estado. Es decir, el arraigo laboral o el social son apreciados en menor medida por el TEDH en los casos en que éste tiene que decidir acerca de si una determinada sanción de expulsión, penal o administrativa, impuesta por un Estado a una persona atendiendo a su normativa interna es conforme a los derechos humanos, a la CEDH y a la jurisprudencia del propio TEDH.

De la casuística del TEDH es posible inferir, siguiendo la Circular FGE 2015, el alcance de dicho concepto material:

Por una parte, un mayor tiempo de residencia en el país de acogida debe entenderse como un mayor arraigo en el mismo. Por eso, la regla general será entender que los residentes legales tienen arraigo, pero no presumirlo, pues el residente legal puede no tener vínculos efectivos en el país a pesar de su saludable condición 
administrativa. En este sentido, una presencia continuada durante un periodo prolongado de tiempo, incluso cuando la entrada y permanencia en el territorio nacional ha sido de forma irregular, pero donde se han creado vínculos efectivos, debe ser considerado arraigo limitativo de la expulsión (Recio Juarez, 2016). Así es, el arraigo no puede deducirse de la simple entrada en España por parte del extranjero en una fecha determinada, sino que se exige la efectiva integración en la sociedad. Es doctrina del TEDH considerar que hay arraigo cuando se da una situación de estancia estable, de cierta entidad y siempre que vaya acompañada de otras circunstancias, especialmente familiares, que impliquen la creación de fuertes vínculos con el país de acogida.

Algo similar se recoge en el apartado b) del art. 57.5 LE. Si bien todos los supuestos de dicho precepto cabe incluirlos en el criterio formal, el referido a los residentes de larga duración es una excepción. Efectivamente, en el apartado b) del art. 57.5 LE parece haber una presunción de arraigo en los residentes de larga duración. Sin embargo, continua el precepto rompiendo esa presunción al establecer que "antes de adoptar la decisión de la expulsión de un residente de larga duración, deberá tomarse en consideración el tiempo de su residencia en España y los vínculos creados, su edad, las consecuencias para el interesado y para los miembros de su familia, y los vínculos con el país al que va a ser expulsado". De esta manera se intenta conocer si además de llevar tiempo en el país, los vínculos adquiridos son efectivos. Pero nótese que para la LE los vínculos efectivos en el país solo se tendrán en cuenta si el sujeto es un residente de larga duración.

Siguiendo con la casuística del TEDH, hay situaciones de asentamiento prolongado que convierten al inmigrante en ciudadano efectivo de un país. Ejemplo de ello serían los mal llamados "inmigrantes de segunda generación", cuando hay relaciones estables de convivencia y dependencia donde una expulsión puede ser una injerencia injustificada, o cuando se tienen parientes próximos como hijos, cónyuge, padres o hermanos (sentencia TEDH 17 de febrero de 2009, Onur contra el Reino Unido) siempre que sea una relación efectiva y no puramente formal (sentencia TEDH de 30 de noviembre de 1999, Baghli contra Francia).

Por otra parte, el TEDH considera importante saber si el expulsable tiene lazos en el país de origen (sentencia TEDH de 12 de enero de 2010, Khan contra el Reino Unido). La carencia de vínculos sociales 
y culturales en origen, como ocurre con frecuencia con los jóvenes en prisión que han sido menores extranjeros no acompañados, es suficiente para entender que dicha persona debe arraigar en el país de acogida y, por tanto, no proceder a su expulsión.

Esta doctrina del TEDH ha sido seguida por algunos tribunales en España antes de la reforma del art. $89 \mathrm{CP}$ donde se ha recogido el arraigo como criterio limitador a la expulsión sustitutiva de la pena de prisión. En concreto, la Audiencia Provincial de Sevilla, en sentencia de 25 de abril de 2012 (sección tercera, número de sentencia: 233/2012), argumenta sobre la necesidad de realizar una lectura en clave constitucional del art. $89 \mathrm{del} \mathrm{CP}$, en la que, aplicando los criterios acogidos en las sentencias del TEDH y en los tratados suscritos por España sobre la materia, se amplíe la excepción a la expulsión, incluyendo un estudio de las concretas circunstancias del penado, su arraigo en nuestro país, la situación familiar y laboral, e incluso los riesgos que pudiera correr ante la posibilidad de ser objeto de torturas o tratos degradantes en su país de origen.

La inclusión del arraigo como elemento limitador de la expulsión penal destierra las dudas sobre el uso del concepto material de arraigo en este ámbito.

\subsubsection{El arraigo como factor de protección frente al delito}

En los últimos tiempos han ido adquiriendo relevancia los vínculos sociales para el cambio de los delincuentes y su desistimiento delictivo (Laub y Sampson, 2003). El fundamento se encuentra en la teoría de los vínculos sociales de Hirschi (1969) que establece la existencia de una serie de contextos en los que las personas se unen a la sociedad mediante mecanismos como el apego, los lazos emocionales de admiración e identificación con otras personas, el compromiso, la asunción de objetivos sociales, la participación en actividades sociales positivas, y las creencias en valores establecidos y contrarios al delito. Desde el punto de vista sociológico se entiende que el arraigo tiene una doble función de protección y de reconocimiento personal (Paugam, 2012).

El comportamiento delictivo puede aparecer si se produce una ruptura de dichos vínculos en algún contexto social, ya que el sujeto se siente desmembrado, carente de proyección y con una identidad mermada. Los vínculos que más favorecen el desistimiento delictivo son las relaciones de pareja positivas y los empleos estables, porque 
refuerzan la conformidad social y las relaciones convencionales, dando lugar a nuevas oportunidades de apoyo social (Laub, Sampson y Wimer, 2006). Juegan un papel similar la transformación de la identidad (que puede venir de la mano de una pareja o de un empleo, entre otras) y el envejecimiento. Estos predictores del proceso de desistimiento se mantienen a pesar de las variaciones en las características individuales. Los adultos que fueron adolescentes con lazos débiles en la sociedad necesitarán un punto de inflexión positivo en sus vidas que les reenganche a la misma (Laub y Sampson, 2003).

Este concepto de arraigo es el que más alcance tiene. No tiene que estar tasado en ninguna norma administrativa, ni tampoco tiene que ser solo familiar como prioriza el TEDH. Con esta aproximación es posible utilizar cualquier relación o acontecimiento que produzca un punto de inflexión en el individuo a partir del cual comience la construcción de una nueva identidad.

\section{EL ARRAIGO Y EL PRINCIPIO DE REINSERCIÓN SOCIAL}

\subsection{Supuestos de intervención penitenciaria}

Por regla general, la expulsión se sitúa en el horizonte de los extranjeros que son condenados a penas de prisión superiores a un año (arts. 89 CP y 57.2 LE). No tendría interés el estudio del arraigo desde la perspectiva criminológica en la ejecución de penas de prisión de extranjeros si no fuera por la existencia de un número significativo de casos en los que, a pesar de la norma general, la expulsión no procede o resulta imposible su ejecución tanto durante la condena como tras su cumplimiento.

El art. 89.8 CP establece que en los casos en los que la expulsión acordada no se pudiera materializar, hay que proceder a ejecutar la pena originariamente impuesta o el tiempo que reste o incluso a la suspensión de la misma si se dieran los requisitos para ello, manteniéndose vigente la doctrina del $\mathrm{TC}$ al respecto en donde se establece que no pudiéndose ejecutar la expulsión, se considerará el cumplimiento del resto de la pena y su posible suspensión en las mismas condiciones que los penados nacionales y extranjeros residentes legales (ATC $\mathrm{n}^{\circ}$ 132/2006, de 4 de abril de 2006).

La Circular 7/2015 FGE llama la atención, además, sobre dos casos: Por un lado, aquellos en los que no se puede materializar 
la expulsión por "voluntad deliberadamente obstruccionista del penado extranjero concretada en actos de rebeldía". En estos casos considera que a efectos de la suspensión de la pena habrá que ponderar tal circunstancia. Por otro lado, hace referencia a los supuestos en los que pasados dos años desde el auto que acuerda la expulsión, ésta no se ha materializado. Se recomienda entonces reconsiderar la expulsión si el extranjero ha experimentado una variación en su situación de arraigo.

Ahondando en la ejecución de la pena de los extranjeros sobre los que no es posible ejecutar la expulsión, parece del todo admisible que si para la suspensión de la misma hay que atender a las circunstancias del caso en las mismas condiciones que un nacional, para el cumplimiento de la ejecución de la pena de prisión entiendo que hay que seguir el mismo criterio y atender al principio de igualdad y no discriminación tanto con respecto al tipo de régimen en el que ha de cumplir la pena, como a las estrategias de tratamiento.

A más abundamiento hay que decir que si la expulsión es una figura que interfiere en la ejecución de la pena en la medida que contribuye con los fines de la política migratoria como expresamente reconoce la Circular 7/2015 FGE basándose en el art. 2 LE, es posible argumentar que desapareciendo las posibilidades de expulsión, la pena debe ejecutarse atendiendo solo y exclusivamente a los fines de la pena. Esto implica que la ejecución de la pena debe orientarse a la reinserción en España, puesto que si no fue posible su expulsión en sede penal, difícilmente podrán ser sorteados los obstáculos para ejecutar la expulsión administrativa tras el cumplimiento de la condena (art. 57.2 LE), salvo por el hecho de que la expulsión penal se basa en un criterio material de arraigo y la administrativa se limita a considerar arraigo solo los supuestos del art. 57.5 LE (criterio formal). La pregunta en este supuesto es si cabe mantener la expulsión de un excondenado con criterios formales en sede administrativa tras el cumplimiento de la pena en aquellos casos en los que en sede penal se ha entendido, con un criterio material de arraigo, que la expulsión no era posible.

\subsection{El arraigo como elemento de decisiones regimentales y tratamentales}

Para los supuestos de los extranjeros regularizados o con arraigo y para los inexpulsables se hace imprescindible que la ejecución 
de la pena se conduzca por el régimen penitenciario acorde a sus necesidades tratamentales. Esto exige que se desarrolle atendiendo al principio de igualdad y no discriminación, sin que su situación administrativa de extranjería sea en sí misma un impedimento. En este sentido, desde Instituciones penitenciarias se hace necesario fomentar los permisos de salida, salidas programas, clasificación regimental y el medio abierto. Para que este deseo se materialice es necesario desterrar la idea de que la "situación irregular" del extranjero inexpulsable es un elemento de desarraigo y se use para denegar los permisos de salida o la ejecución en medio abierto. Es cierto que la Administración penitenciaria tiene el deber legal de colaborar en la expulsión del extranjero para favorecer la realización de la política migratoria, pero solo cuando aquel es expulsable. En la medida en que no es posible ejecutar la expulsión por los diferentes motivos ya aludidos, la ley y la jurisprudencia igualmente obligan a usar criterios tratamentales, y no administrativos formales, para tomar decisiones relativas al tipo de régimen y a las necesidades de tratamiento del penado.

Hay que tomar en consideración que la irregularidad administrativa no es una característica del sujeto y, en ocasiones, ni siquiera de su situación de arraigo en el país. Obedece a criterios formales administrativos que tienen que ver con el control de fronteras. Además no es un estado inamovible. Por el contrario, es habitual que los extranjeros pasen de una situación irregular a otra regular en distintas fases de su vida, y que en ocasionas quien estaba en situación regular pierda dicha autorización por diferentes motivos. Por tanto, la falta de documentación, la ausencia de autorización administrativa de residencia o, incluso, la existencia de un decreto de expulsión no deberían suponer un obstáculo en el régimen y tratamiento penitenciarios de un extranjero, aún cuando así se desprende de la Instrucción 1/2012 de la Subdirección General de Tratamiento y Gestión Penitenciaria y en la Circular 1/2013 del Departamento de Justicia de la Generalitat de Cataluña.

De la opinión de que la situación administrativa del extranjero no debe derivar en un trato diferente es la Audiencia Provincial de Barcelona, que de forma reiterada aporta argumentos en este sentido. Concretamente en el Auto $n^{\circ}$ 1275/2015, de 14 de agosto de 2015, señala que “...no existen inconvenientes de índole tratamental para la concesión de permisos de salida... ya ha señalado la Sala en muchas ocasiones que la situación administrativa de los extranjeros 
en prisión no puede ser tratada de forma general y sin atender a la evolución penal y penitenciaria concreta en cada caso...fundar el mal pronóstico... en esta circunstancia puede implicar una denegación arbitraria de permiso...".

El derecho penitenciario español se basa en un sistema progresivo que forma parte del tratamiento. De hecho, según los artículos 154 y 156 de Reglamento penitenciario los permisos son instrumentos de preparación para la vida en libertad. Por lo que difícilmente puede entenderse que una autorización administrativa condicione esa orientación resocializadora constitucionalmente establecida. En este sentido, es cierto que una de las herramientas para la concesión de la libertad condicional a los extranjeros es el Acuerdo del Consejo de Ministros de 2005 sobre autorización de permisos temporales de trabajo. Si bien este Acuerdo permite trabajar en España a personas extranjeras que de acuerdo con la legislación de extranjería no podrían hacerlo por no estar autorizadas administrativamente, es posible aproximarse a esta realidad desde otra perspectiva. $\mathrm{Me}$ refiero a considerar la ley de extranjería como subsidiaria a la legislación penitenciaria, y mantener que la actividad laboral de los penados, con independencia de su situación administrativa, es un elemento esencial para el tratamiento penitenciario y la adquisición de vínculos de cara a la reinserción del sujeto. Los requisitos establecidos en dicho Acuerdo para que un extranjero pueda acceder a la libertad condicional son muy restrictivos, siendo difícil que alcance a un número considerable de extranjeros.

\subsection{El arraigo como objetivo del tratamiento penitenciario}

En paralelo a lo anterior, el tratamiento penitenciario es una herramienta de primer orden de cara a la creación y fortalecimiento de vínculos familiares y sociales desde una perspectiva criminológica enfocada al desistimiento delictivo. Con independencia de si en la sentencia condenatoria se ha considerado la existencia o no de arraigo o de que el sujeto esté incurso en una causa de expulsión tras cumplir su condena en España, la atención al arraigo desde una perspectiva más amplia, buscando anclajes en la comunidad que sirvan de inhibidores del delito, debe ser un objetivo primordial en el tratamiento penitenciario de los extranjeros, especialmente si no va a ser posible la materialización de su expulsión. Los permisos de 
salida y el medio abierto son evidentemente instrumentos adecuados para la creación y fortalecimiento de estos lazos. Pero estos no son los únicos mecanismos a considerar. La tarea propuesta no es fácil de concretar y requiere de mayor profundización. Tal vez algunos perfiles de presos como, por ejemplo, los jóvenes extranjeros que han sido previamente tutelados por el sistema de protección por haber sido menores no acompañados (García España, 2016), estén en mejores condiciones para este tipo de abordaje. En cualquier caso, el tercer escenario sobre el que centramos esta reflexión no deja de ser un auténtico reto para al ámbito penitenciario.

\section{CONCLUSIONES}

Sociológicamente han sido muchos los autores que han mostrado la construcción de la etiqueta "extranjero delincuente" y sus consecuencias. Entre estas últimas se destaca el uso de la misma para justificar medidas penales y administrativas excepcionales, llegando a condicionar las posibilidades de reinserción. Con ocasión de la reforma de $2015 \mathrm{del}$ art. $89 \mathrm{CP}$ en donde se introduce el arraigo de la persona extranjera como elemento limitador de la expulsión, se reflexiona sobre el uso del concepto material de arraigo de las personas extranjeras presas con varias finalidades.

Una de ellas es evitar la expulsión en aquellos supuestos en los que el paso del tiempo derivaría en un nuevo estudio de sus circunstancias de arraigo (criterio de la FGE). En estos casos, se alienta a aprovechar el tiempo de estancia de la persona extranjera en prisión para trabajar vínculos sociales en España dados los casos en los que la expulsión, como sustitutivo de la pena, se demora sustancialmente en el tiempo.

La otra finalidad es que, en caso de que no se llegue a materializar la expulsión, los vínculos que se han ido forjando en el contexto de acogida deriven en un desestimiento delictivo posterior.

Y el último fin perseguido, más centrado en la reinserción concreta, sería poder estimular la reflexión en el ámbito administrativo sobre la respuesta que desde la ley de extranjería se da a las personas extranjeras que han cumplido condena en España. No tiene sentido que en el ámbito penal y penitenciario se atienda a un concepto material y amplio del concepto de arraigo, y una vez cumplida la 
condena se acuda a un concepto formal y más restrictivo de arraigo que trunque las expectativas forjadas en el ámbito penitenciario.

Por tanto, el concepto de arraigo no sería únicamente una circunstancia del sujeto a partir de la cual decidir si se expulsa o no al condenado, sino que se propone como un objetivo primordial de la intervención penitenciaria para los extranjeros inexpulsables condenados a prisión. Como no se sabe a priori si la expulsión acabará siendo materializada, interesa trabajar con ese mismo objetivo sobre los extranjeros a los que se les ha sustituido la pena de prisión por la expulsión. Es así de acuerdo a la Circular 2015 de la FGE en donde se recomienda la revisión de los supuestos en los que pasados dos años desde el auto que acuerda la expulsión, ésta no se ha materializado. La revisión se orienta a conocer si el extranjero ha experimentado una variación en su situación de arraigo.

Por otra parte, el número de extranjeros sobre los que no se materializa la expulsión debe hacer reflexionar a Instituciones penitenciarias sobre los criterios que usa en la clasificación regimental de los extranjeros y en las decisiones tratamentales. La situación de irregularidad administrativa o el decreto de expulsión no es presunción de falta de arraigo, ni debería condicionar el tratamiento y el régimen penitenciario. En este sentido, se debería también reconsiderar por parte del Consejo de Ministros los requisitos para autorizar permisos temporales de trabajo al apreciarse este como un elemento esencial del tratamiento.

Por último, hay que recordar que tras el cumplimiento de condena entra en escena el art. 57.2 LE que obstaculiza seriamente las posibilidades de reinserción del extranjero al establecer como causa de expulsión contar con antecedentes penales. Convendría una reforma de tal precepto en donde se pudiera incluir, al menos, algunas excepciones referidas al arraigo material del sujeto que ha impedido su expulsión en sede penal y evitar que el único concepto de arraigo que se use sea el formal del artículo 57.5 LE.

\section{REFERENCIAS}

Balance anual de LUCHA CONTRA LA INMigRación IRREgular, 2013. http://www. interior.gob.es/documents/10180/1207668/balance_2013_inmigracion_ irregular.pdf/132387b3-d93b-4485-8a5b-1a734359764c 
Balance anUal DE LUCHA CONTRA LA INMigración IRREgular, 2014. http://www. interior.gob.es/documents/10180/3066430/Balance+2014+de+la+lucha+contra+la+inmigración+irregular/4a33ce71-3834-44fc-9fbf-7983ac e6cec4

Balance anUal DE LUCHA CONTRA LA INMIGRACiÓN IRREgUlaR, 2015. http://www. interior.gob.es/documents/10180/6331509/bal_inm_irregular_2015. pdf/3065f952-613f-42af-bc5a-9d6c1c127cd1

Boza Martínez, D. (2016): La expulsión de personas extranjeras condenadas penalmente: El nuevo artículo 89 CP. Thomson Reuters Aranzadi.

Brandariz García, J. A. (2011): Sistema penal y control de los migrantes. Gramática del migrante como infractor penal. Comares. Granada.

Brandariz, J. A. (2015): La evolución del sistema penitenciario español, 1995-2014: Transformaciones de la penalidad y modificación de la realidad. Revista Crítica Penal y Poder, $\mathrm{n}^{\circ}$ 9. Septiembre.

Cerezo Domínguez, A. I. y Arenas García, L. (2016). Estudio longitudinal del tráfico de drogas y de su impacto en la delincuencia. InDret. http:/www. indret.com/pdf/1196.pdf

Caldwell, B. (2016): Demonización de los extranjeros delincuentes. http:// crimmigration.com/2016/10/25/the-demonization-of-criminal-aliens/

Carbajal García, P. (2012): El concepto jurídico de arraigo en la Doctrina Judicial. Revista de Derecho Migratorio y Extranjería.

http://www.asesoriayempresas.es/articulo/JURIDICO/127371/el-conceptojuridico-de-arraigo-en-la-doctrina-judicial.

Cid Moliné, J. (en prensa). European criminal policy and Spanish prison practice: understanding confluences and gaps. In: T. DAEMS, L. RoBERT (eds) Europe in prisons. London: MacMillan.

CirCUlar 7/2015, sobre la expulsión de ciudadanos extranjeros como medida sustitutiva de la pena de prisión tras la reforma operada por L.O. 1/2015. http://www.cvca.es/wp-content/uploads/2015/11/expulsion_sustitutiva. pdf

Circular 1/2013 de modificación de la Circular 1/2011, sobre estrangeria als centres penitenciaris de Catalunya

http://www.derechopenitenciario.com/comun/fichero.asp?id=2896

Daunis Rodríguez, A. (2015): Las cárceles de los excluidos y marginados. Situación de los centros de internamiento de extranjeros tras la aprobación de su reglamento. Revista de Derecho migratorio y Extranjería. № 40. https://dialnet.unirioja.es/servlet/articulo?codigo $=5317558$

Daunis Rodríguez, A. (2016): La ocupación carcelaria. Hipótesis acerca del descenso de la población penitenciaria en España. Estudios Penales y Criminológicos, vol. XXXVI. Pp. 447-483.

De Lucas, J. (2003): Inmigración y globalización acerca de una política de inmigración. REDUR, $\mathrm{n}^{\circ} 1$.

Díaz Fraile, F. (2015): Derecho Penal y Derecho Administrativo sancionador. Garantías y límites en la jurisprudencia del TEDH. $1^{\text {a }}$ Edición. Editorial Tirant lo Blanch. Valencia. Págs. 94 y 95. 
Díez Ripollés, J. L. (2008): De la sociedad del riesgo a la seguridad ciudadana: Un debate desenfocado. Revista brasileira de ciências criminais, $\mathrm{n}^{\mathrm{o}} 71$.

GARCía España, E. (2016): De menores inmigrantes en protección a jóvenes extranjeros en prisión. InDret 3/2016. http://www.indret.com/pdf/1231. pdf

García España, E. (coord., 2017): Razones para el cierre de los CIE: Del reformismo a la abolición. Informe OCSPI. https://ocspi.files.wordpress. com/2017/07/razones-para-el-cierre-de-los-cie-del-reformismo-a-la-abo licion.pdf

GonzÁlez TAscón, M. M. (2016): La cuarta reforma del artículo 89 del Código Penal relativo a la expulsión del extranjero condenado a pena de prisión. Estudios Penales y Criminológicos. http://www.usc.es/revistas/index.php/ epc/article/view/2674

Hirschi, T. (1969): Causas de la delincuencia. Berkeley y Los Angeles: University of California Press.

INSTITUCIONES PENITENCIARIAS (2015): Informe General

http://www.institucionpenitenciaria.es/web/export/sites/default/datos/descargables/publicaciones/Informe_General_2015_acc.pdf

Larrauri Pijoan, E. (2016): Antecedentes penales y expulsión de personas inmigrantes. InDret, $\mathrm{n}^{\circ} 2$. http://www.indret.com/pdf/1214.pdf

Laub, J. y Sampson, R. (2003): Life-course desisters? Trajectories of crime among delinquent boys followed to age 70. Criminology, 41, 301-340. http://scholar.harvard.edu/files/sampson/files/2003_crim_laub_1.pdf

Laub, J., Sampson, R y Wimer, C. (2006): Does marriage reduce crime? A counterfactual approach to within-individual causal effects. Criminology, 44, 465-506. http://scholar.harvard.edu/files/sampson/files/2006_cri minology_laubwimer_1.pdf

Martínez Escamilla, M. (2016): Centros de internamiento para extranjeros: Estado de la cuestión y perspectivas de futuro. Revista electrónica de Ciencia Penal y Criminológica, 18-23. http://criminet.ugr.es/recpc/18/recpc18-23.pdf

Mecanismo Nacional contra la Tortura. Informes 2013, 2014 y 2015. https:// www.defensordelpueblo.es/informe-mnp/mecanismo-nacional-prevencion-la-tortura-informe-anual-2015/

Ministerio Del Interior. Anuario estadístico de 2014. http://www.interior. gob.es/documents/642317/1204854/Anuario-Estadistico-2014_v201510. pdf/0c18a800-f7f7-405c-9155-7391633618c8

Montero Pérez de Tudela, E. y Nistal Burón, J. (2014): La población penitenciaria extranjera en España: evolución y características. Revista de Derecho Migratorio y de Extranjería, no 37.

Montero Pérez de Tudela, E. y Ravagnani, L. (2016). La población penitenciaria en España e Italia. Estudio comparativo de la situación de la población carcelaria entre ambos países. RECPC 18-09. http://criminet.ugr.es/ recpc/18/recpc18-09.pdf 
Nistal Burón, J. (2013): Los fines de la política criminal y su vinculación con la política de extranjería en la reforma proyectada del Código Penal. Su incidencia en el ámbito penitenciario. Diario La Ley, nº 8143.

OBSERVATORIO DEL SISTEMA PENAL HACIA LA INMIGRACIÓN. https://ocspi.wordpress. com

Paugam, S. (2012): Protección y reconocimiento. Por una sociología de los vínculos sociales. École des Hautes Études en Sciences Sociales. Vo. 2012/2. http://www.ehu.eus/ojs/index.php/papelesCEIC/article/view/12453

Recio JuÁRez, M. (2016): La expulsión de extranjeros en el proceso penal. $1^{\mathrm{a}}$ Edición. Editorial Dykinson.

Ríos Martín, J. (2014): Espacio de vulneración de Derechos Humanos. Revista Crítica. Noviembre-diciembre 2014. No 994.

Roig Torres, M. (2014): La expulsión de los extranjeros en el proyecto de reforma del Código penal. Análisis desde la perspectiva del TEDH. Unas notas sobre el Derecho británico. Estudios penales y criminológicos. Vol. XXXIV. Pp. 423-509. http://www.usc.es/revistas/index.php/epc/article/ view/2114

Servicio Jesuita a Migrantes (SJM). Informe CIE 2016: "25,66 media diaria de repatriaciones forzadas” http://www.sjme.org/files/informecie16.pdf

Solanes Corella, A. (2016): Un análisis crítico de los centros de internamiento de extranjeros en España: Normativa, realidad y alternativas. Revista Telemática de Filosofía del Derecho, no 19.

STUMPF, J. (2006): The crimmigration crisis: Immigrants, crime, and sovereign power. American University Law Review, vol. 56:2.

Visher, C. A. y Travis, J. (2003): Transitions from Prison to Community. Understanding Individual Pathways. Annual Review of Sociology. 2003. 29:89-113 http://canatx.org/rrt_new/professionals/articles/VISHER-PRI SON \%20TO\%20COMMUNITY.pdf

WORLD PRISON BRIEF http://www.prisonstudies.org/world-prison-brief-data

Yáñez Velasco, R. (2015): Extranjero y proceso penal. Controversias sobre la expulsión del territorio nacional. $1^{\text {a }}$ Edición. Editorial Reus. Madrid. 